27(4), 523-541

\title{
The Analysis of Roll Call Data from the 18th Korean National Assembly: A Bayesian Approach
}

\author{
Kyu S. Hahn ${ }^{a} \cdot$ Yuneung $\operatorname{Kim}^{b} \cdot{\text { Jongho } \operatorname{Lim}^{c} \cdot J \text { Johan } \operatorname{Lim}^{b} \cdot \text { Suhyun Kwon }}^{d}$ \\ - Kyeong Eun Lee ${ }^{e, 1}$ \\ ${ }^{a}$ Department of Communication, Seoul National University \\ ${ }^{b}$ Department of Statistics, Seoul National University \\ ${ }^{c}$ Department of Statistics, Iowa State University \\ ${ }^{d}$ Department of Political Science and International Relations, Korea University \\ ${ }^{e}$ Department of Statistics, Kyungpook National University
}

(Received February 19, 2014; Revised April 15, 2014; Accepted June 16, 2014)

\begin{abstract}
We apply a Bayesian estimation procedure to the analysis of roll call voting records on 2,389 bills processed during the 18th Korean National Assembly. The analysis of roll calls yields useful tools for to combining the measurement of legislative preference with the models of legislative behavior. The current Bayesian procedure is extremely flexible, applicable to any legislative setting, irrespective of the extremism of the legislator's voting history or the number of roll calls available for analysis. It can be applied to any legislative settings, providing a useful solution to many statistical problems inherent in the analysis of roll call voting records. We first estimate the ideal points of all members of the 18th National Assembly and their confidence intervals. Subsequently, using the estimated ideal points, we examine the factional disparity within each major party using the estimated ideal points. Our results clearly suggest that there exists a meaningful ideological spectrum within each party. We also show how the Bayesian procedure can easily be extended to accommodate theoretically interesting theoretical models of legislative behavior. More specifically, we demonstrate how the estimated posterior probabilities can be used for identifying pivotal legislators.
\end{abstract}

Keywords: 18th National Assembly, Bayesian model, ideal points, legislative behavior, roll call.

\section{1. 서론}

국회에서 수행되는 기명투표는 국회의원들의 정치성향에 대한 연구의 매우 중요한 자료가 되며 특히 의 원들의 정책선호도를 측정하고 검증하는데 유용하게 활용된다. 기명투표의 분석은 투표결과의 유사성 을 바탕으로 의원들과 법안들을 가상의 동일한 '정책공간'에 위치시키고 이 공간에서 각 의원의 위치를 '최대선호점'이라 정의한다. 최대선호점은 의원들의 개인적 선호 또는 유권자의 선호등 다양한 요인들 의 결과물로 간주될 수 있다.

This research was supported by National Research Foundation of Korea(NRF) grant funded by the Korea government(NRF-2012R1A1A3013075).

${ }^{1}$ Corresponding author: Department of Statistics, Kyungpook National University, 80 Daehakro, Buk-Gu, Daegu 706-701, Korea. E-mail: artlee@knu.ac.kr 
의회 구성원들의 표결행태를 분석하여 최대선호점(ideal point)을 추정하는 것은 현대 의회연구에서 가 장 기본적인 연구이다. 의원들의 최대선호점을 분석하는 것이 중요한 이유는 크게 두 가지이다. 우선 의원들의 최대선호점 추정값의 분포를 통해 의원들 간의 차이가 당파성이나 지역과 같은 특별한 요인 을 반영하고 있는지를 알 수 있고 또한 시간의 흐름에 따른 양극화 현상을 살필 수 있기 때문이다 (McCarty 등, 2001). 양극화 현상과 관련하여 지난 30여 년간 많은 연구자들이 미국 의회의 기명투표(roll call voting) 결과를 분석하여 미국 정치가 얼마나 양극화되어 왔는지를 경험적으로 보여주었다. 예를 들어, Schlesinger (1985)는 미국 하원에서 점진적으로 정당투표가 늘어난 것을 증명하였으며, 그의 연 구결과에 따르면 민주당의 경우, 그 동안 관측된 적이 없는 수준의 당내 통일성을 1983 년에 보인 것 으로 나타났다. 마찬가지로 1959년부터 1980년 사이의 기명투표 결과를 분석한 Poole과 Rosenthal (1984)은 상원에서도 민주당과 공화당 양당 의원들이 점진적으로 양극화되는 방향으로 이동하였음을 보 였다. Rohde (1991)를 비롯한 다른 연구자들 (Carmines와 Stimson, 1989; Adams, 1997; Layman, 2001; Abramowitz과 Saunders, 1998)도 Poole과 Rosenthal (1984)가 제안한 W-NOMINATE 점수를 활용하여 정당 사이의 양극화 현상이 시간이 지남에 따라 심화되어 왔다는 결과를 증명하고 있다. 이들 연구들은 정교하고 표준화된 최대선호점 추정 기법의 개발이 의정연구에 있어 매우 중요함을 시사하고 있다.

최대선호점 추정이 정치학 연구에서 중요한 또 하나의 이유는 기명투표 분석으로부터 나온 추정값들이 의원들의 입법행태와 관련된 이론들을 검증하는 데 사용될 수 있기 때문이다. 계량적 분석을 통해 의원 들의 표결행태를 추측하는 것은 객관적으로 입법지식을 축적 할 뿐만 아니라 또한 의원들의 추정된 최대 선호점을 정치학의 주요 연구들의 기본 자료로 활용 할 수 있다. 실제로 이런한 기명투표의 분석 방법들 은 호주 (Jackman, 2001) 등 의회 민주주의가 발달된 선진국은 물론, 체코공화국 (Noury와 Mielcova, 1997), 폴란드 (Mercik와 Mazurkiewicz, 1997), 러시아 (Myagkovb와 Kiewiet, 1996), 라틴 아메리카 국가들 (Carey, 2003; Desposato, 2003; Londregan, 2000; Morgenstern, 2003), 더 나아가 유럽 의회 (Hix, 2001; Noury, 2002)와 유엔 (Voeten, 2000) 등에서 이뤄진 표결에 대하여도 적용되고 있다.

다양한 학술적 유용성에도 불구하고 아직까지 국내에서는 기명투표 결과를 활용한 연구들이 극히 제한 적인 실정이며, 분석을 위한 방법론이 논의된 적도 거의 전무한 상황이다. 주된 이유 중에 먼저 2005 년 까지 의회기명투표결과에 대한 기록이 거의 존재하지 않았다는 점이다. 국회에 전자투표장치가 처음 설 치된 시기는 박정희 정권 시절인 지난 1975 년 8 월로 거슬러 올라간다. 그러나 부정투표 가능성 문제로 국회 본회의장 표결이 전자투표로 정착되는 과정은 쉽지 않았다. 김영삼 정부 시절인 1994년 6월에 전 자투표가 기명투표의 한 방법으로 국회법에 명기되었고, 1997 년 5 월에는 10 억원 가까운 예산을 들여 본 회의장에 전자투표 장치를 설치하였으나 곧바로 활용되지 못하였다. 의원들이 자신의 찬.반투표 내용 이 공개되는 것을 꺼렸기 때문이다. 우여곡절 끝에 2000 년 2 월 전자투표를 본회의의 일반적인 표결방법 으로 하는 국회법 개정안이 통과되었고, 전자투표 시스템의 개보수를 거쳐 노무현 정부 시절인 2005 년 9 월 1 일에 '디지털 본회의장' 구축이 완료됨으로써 전자투표가 기명투표의 일반화된 방식으로 자리 잡 기에 이르렀다. 따라서 2005 년 이전의 표결기록을 분석하는 것은 원천적으로 불가능하며 국회 표결기 록에 대한 학술적 관심이 높아진 것은 비교적 최근의 일이라 할 수 있다.

의회표결 분석이 활성화되지 못한 다른 이유는 한국 의회정치의 특성상 당론에 의한 투표가 개별 의원들 의 투표행태에 지배적 영향을 미치며, 의원들 간의 차이도 거의 존재하지 않을 것이라는 일부 학자들의 선입견에 있다. 실제로 한국 의회 표결과정의 가장 큰 특징 중 하나가 바로 공식적인 '당론'의 존재이다. 각 정당의 지도부가 상당수 법안에 대해 당론을 정하고 이를 소속 의원들에게 알려 당론에 따라 투표하 도록 하는 것은 한국 정당정치의 특이한 현상으로 볼 수 있다. 투표행태에 있어 정당 간 양극화는 한국 의회에만 국한된 현상이 아니다. 그렇다면 한국 의회의 정당 간 양극화 정도가 어느 정도이며, 이런 당 
론에 따른 투표행태와 실제 개별 의원들의 정책선호도 사이에 어떤 관계가 존재하는지 여부는 실제 자료 분석에 근거해 결론을 내릴 수 있는 문제이다.

실제로 각 정당들이 모든 법안에 대해 당론을 가지고 있는 것은 아니며, 당론이 존재하는 경우에도 해 당 정당 소속 의원들의 당론에 따른 투표비율이 높기는 하나, 당론 준수 여부에 있어 의원들 간에 상당 한 차이가 있는 것으로 알려져 있다. 미국에서도 공식적인 당론은 존재하지 않으나 의원들이 소속 정당 의 다수의견을 당론으로 간주할 경우 당론투표 비율이 매우 높다는 연구 결과가 일반적으로 받아들여지 고 있다. 따라서 당론이 유권자들의 권익을 대변하는 데 어떠한 영향을 미치고 있는지를 연구함에 있어 기명투표자료의 정확한 분석은 매우 중요하다고 볼 수 있다.

정치학에 존재하는 대부분의 기명투표에 대한 모형들은 Downs (1957)가 처음 소개한 공간모형의 개념 을 기초로 발전되어 왔다. 기명투표의 공간모형은 제안된 법안들과 각 의원들을 가상의 정책공간에 위 치한 점들을 통하여 표현하게 된다.

조금 구체적으로 살펴보면, 각 법안들의 제안사항에 대하여 '찬성'(법안대로 변경)과 '반대'(현 상태 유 지)의 두 점을 배치하고 각 의원들에 대하여 해당의원의 정치성향을 가장 잘 표현하는 하나의 점(최대 선호점)을 대응시키기고 이 점들을 실제 기명투표자료로부터 추정하게 된다. 공간모형에서 특정 법안 에 대한 의원의 찬성/반대-효용(utility)은 의원 자신의 최대선호점과 해당 법안의 찬성/반대-대응점과 의 거리가 멀어질수록 감소하도록 정의된다 (Davis 등, 1970).

즉, 각 법안 $(j=1, \ldots, m)$ 에 대하여 '찬성' 입장을 $\boldsymbol{\zeta}_{j}$, '반대' 입장을 $\boldsymbol{\psi}_{j}$ 라고 가정한다면 각 의원 $(i=$ $1, \ldots, n)$ 의 각 입장에 대한 효용(utility)은 각 의원의 최대선호점 $\mathbf{x}_{i}$ 의 이차 손실함수로 표현된다.

$$
\begin{gathered}
U_{i}\left(\boldsymbol{\zeta}_{j}\right)=-\left\|\mathbf{x}_{i}-\boldsymbol{\zeta}_{j}\right\|^{2}, \\
U_{i}\left(\boldsymbol{\psi}_{j}\right)=-\left\|\mathbf{x}_{i}-\boldsymbol{\psi}_{j}\right\|^{2} .
\end{gathered}
$$

따라서, $U_{i}\left(\boldsymbol{\zeta}_{j}\right)>U_{i}\left(\boldsymbol{\psi}_{j}\right)$ 라면 $i$ 의원은 $j$ 법안에 대해 '찬성' 표결을 하고 그렇지 않다면 '반대' 표결을 한다고 가정한다. 물론 이러한 모형은 개념적으로 '진실한 투표(sincere voting)'가 존재한다는 가정을 필요로 한다.

위에 기술된 공간모형에서는 법안의 수가 증가할수록 모수의 수가 증가하는 어려움이 있어 현재 사용되 는 통계적 방법들은 다양한 문제점들을 지니고 있다. 먼저 가장 많이 알려진 W-NOMINATE (Poole과 Rosenthal, 1997)의 분석 방법은 추정량(최대선호점)의 표준오차의 계산이 어렵고 제안된 추정량의 일 치성 또한 보장되지 못한다 (Clinton 등, 2004). 이런 표준오차의 문제는 2004년 미국 대선과정에서 여러 문제점을 야기하였다. 미국의 정치 전문 잡지인 National Journal에서는 매년 상원과 하원 의원 들이 주요법안에 표결한 기록을 분석하여 각 의원들의 '이념성향'을 추정하여 발표하고 있다. National Journal에서는 2003년에 처리된 법안 중 전문가 그룹이 주관 적 기준을 통해 '주요법안'으로 분류한 31 개 법안에 근거하여 2004년 대선 당시 민주당 후보였던 존 케리(John Forbes Kerry) 메사추세츠 주(州) 상원의원을 2003 년 상원에서 가장 진보적인 의원으로 분류 하였고 이 결과가 언론을 통해 대대 적으로 보도되었다. 이것은 선거기간 내내 케리 후보가 부시 후보 진영의 공격을 받는 원인을 제공하였 다.

이와 관련해 Clinton 등 (2004)는 의회표결 분석에 있어 분석방법의 재검토 필요성을 제기했다. 저자 들은 National Journal에서 선정한 31개 법안의 투표결과를 베이즈(Bayesian) 기법을 적용하여 재분 석하였다. 저자들의 분석결과는 선거과정에서 나온 부시 후보 측의 공격과 언론지상에서 연일 보도된 논쟁의 허구성을 보여주었다. 케리 후보가 상당히 진보적인 의원이었던 것은 사실이나 이념성향 점수 에 대한 통계적 신뢰구간이 매우 넓어 '상원에서 가장 진보적인 의원'으로 분류할 만한 근거는 없었으며 
2003년 선거운동으로 많은 법안의 표결에 불참으로 인하여, 케리 후보의 투표성향을 추정하기에는 정보 가 충분하지 않았다. 반면, 케리 후보가 표결에 참여했던 법안들의 경우, 양 당이 첨예하게 대립하여 민 주당 입장에서는 대선후보인 케리 의원의 표결참여가 절실하게 필요했던 법안들이 대부분이었다. 이로 인해 케리 후보의 표결성향이 실제보다 더 진보적으로 보이는 착시효과가 나타났던 것이다. 결론적으로 2004년 미국 대선에서 일어난 진보 논쟁은 의회표결 기록을 분석하는 데 있어 각 의원들의 최대선호점 추정량에 대한 합리적인 신뢰구간 구축의 필요성을 보여주는 매우 적절한 예라 할 수 있다.

이러한 기존 방법론들의 결정적 결함을 보완하면서 한국 국회의 기명투표에 관한 일반화된 분석방법론 을 제시하기 위해 본 연구에서는 Clinton 등 (2004)가 제안한 베이즈 기법을 한국 국회의 기명투표 자료 의 분석에 수정 적용하여 보았다. 잘 알려진 바와 같이 베이즈 방법은 추론하고자 하는 변수가 많고 확 률적으로 복잡한 구조를 지닌 자료에 대한 유용한 방법으로 한국 국회의원들의 다양한 투표행태에 대한 추론을 가능하게 해준다.

\section{2. 방법론}

\section{1. 기명투표 분석을 위한 통계모형}

일반적으로 의회의 표결자료는 $n$ 명의 의원들이 $m$ 개의 다른 법안에 투표한 결과로 구성 되어 있다. 각 법안 $(j=1, \ldots, m)$ 에 대하여 각 의원들 $(i=1, \ldots, n)$ 이 찬성과 반대의 두 가지 선택권을 가진다는 가 정 하에 의회표결자료를 지시변수 $y_{i j}$ 를 이용해 다음과 같이 나타낼 수 있다. 만약 $i$ 번째 의원이 $j$ 번째 법안에 찬성을 했을 때는 $y_{i j}=1$, 반대를 했을 때는 $y_{i j}=0$ 의 값을 가지게 된다. 제안된 공간 투표모 형에서는 각 의원들은 저차원( $d$ 차원 $)$ 의 정책공간 $\left(R^{d}\right)$ 에서 자신의 정치성향을 대변하는 '최대선호점'을 가지며 각 법안들 또한 같은 정책공간에서 법안에 대한 '찬성'과 '반대'의 두 점을 통하여 표현되게 된다. 이때 $i$ 번째 의원이 $j$ 번째 법안에 대하여 찬성의(또는 반대의) 의견을 제시할 확률은 해당의원의 최대선 호점 $\left(\mathbf{x}_{i}\right)$ 과 법안의 찬성점 $\left(\boldsymbol{\zeta}_{j}\right.$, 정책공간에서 ' $\mathrm{Yea'} \mathrm{위치)과의} \mathrm{거리} \mathrm{또는} \mathrm{반대점}\left(\boldsymbol{\psi}_{j}\right.$, 정책공간에서 'Nay' 위치)과의 거리에 대한 함수로 정의 되게 된다.

공간투표모형 이론에서 제시하는 효용함수는 엄밀한 함수적 형태로 명시되어 있지 않은데 본 연구에 서는 의원들의 효용에 대해 정규오차(normal errors)를 갖는 이차효용함수를 가정한다 (Clinton 등, 2004). 이차효용함수는 $U_{i}\left(\boldsymbol{\zeta}_{j}\right)=-\left\|\mathbf{x}_{i}-\boldsymbol{\zeta}_{j}\right\|^{2}+\eta_{i j}$ 와 $U_{i}\left(\boldsymbol{\psi}_{j}\right)=-\left\|\mathbf{x}_{i}-\boldsymbol{\psi}_{j}\right\|^{2}+\nu_{i j}$ 이며, 여기 서 $\mathbf{x}_{i} \in R^{d}$ 은 $i$ 번째 의원의 최대선호점이며, \|\| 은 유클리드 놈(Euclidean norm)이다. 이때 만약 $U_{i}\left(\boldsymbol{\zeta}_{j}\right)>U_{i}\left(\boldsymbol{\psi}_{i j}\right)$ 이면, $y_{i j}=1$, 그렇지 않으면 $y_{i j}=0$ 일 때 효용이 극대화된다.

모형의 설정은 오차에 분포(distribution) 가정을 부여함으로써 완성되는데 오차 $\eta_{i j}$ 와 $\nu_{i j}$ 는 $\mathrm{E}\left(\eta_{i j}\right)=$ $\mathrm{E}\left(\nu_{i j}\right)$ 이고, $\operatorname{Var}\left(\eta_{i j}-\nu_{i j}\right)=\sigma_{j}^{2}$ 인 결합정규분포(joint normal distribution)를 가지며 오차는 의원과 기명투표 모두에 대해 독립적이라고 가정한다 (Clinton 등, 2004). 기존의 표결결과 분석에서는 확률적 교란항(stochastic disturbance)에 대한 몇 가지 서로 다른 규격이 사용되어 왔다. Poole과 Rosenthal (1997)은 극단값 분포(extreme value distribution)를 따르는 오차를 가진 가우시안 효용(Gaussian utilities)을 가정했고 Heckman과 Snyder (1997)는 한 의원에 대해서는 균등오차(uniform errors)를 가 진 이차효용을, 다른 의원에 대해서는 비확률적 효용(nonstochastic utility)을 가정했다. 두 방법론으 로 추정된 최대 선호점에 따라 의원들을 나열했을 때 실질적인 차이는 미미하다.

Clinton 등 (2004) 연구에 기술된 바와 같이 $i$ 번째 의원이 $j$ 번째 법안에 찬성할 확률은 아래와 같이 표 현될 수 있다.

$$
P\left(y_{i j}=1\right)=P\left(U_{i}\left(\boldsymbol{\zeta}_{j}\right)>U_{i}\left(\boldsymbol{\psi}_{j}\right)\right)
$$




$$
\begin{aligned}
& =P\left(\nu_{i j}-\eta_{i j}<\left\|\mathbf{x}_{i}-\boldsymbol{\psi}_{j}\right\|^{2}-\left\|\mathbf{x}_{i}-\boldsymbol{\zeta}_{j}\right\|^{2}\right) \\
& =P\left(\nu_{i j}-\eta_{i j}<2\left(\boldsymbol{\zeta}_{j}-\boldsymbol{\psi}_{j}\right)^{\prime} x_{i}+\boldsymbol{\psi}_{j}^{\prime} \boldsymbol{\psi}_{j}-\boldsymbol{\zeta}_{j}^{\prime} \boldsymbol{\zeta}_{j}\right) \\
& =\Phi\left(\boldsymbol{\beta}_{j}^{\prime} \mathbf{x}_{i}-\alpha_{j}\right),
\end{aligned}
$$

여기서 $\boldsymbol{\beta}_{j}=2\left(\boldsymbol{\zeta}_{j}-\boldsymbol{\psi}_{j}\right) / \sigma_{j}, \alpha_{j}=\left(\boldsymbol{\zeta}_{j}^{\prime} \boldsymbol{\zeta}_{j}-\boldsymbol{\psi}_{j}^{\prime} \boldsymbol{\psi}_{j}\right) / \sigma_{j}, \Phi(\cdot)$ 은 표준정규분포(standard normal distribution)의 누적분포함수를 나타낸다. 이 식은 의원의 최대선호점과 관련해 미관찰된 회귀변수 $\mathbf{x}_{i}$ 를 가 진 프로빗모형 (probit model)과 비슷하다. 계수벡터 $\boldsymbol{\beta}_{j}$ 정책공간에서 $j$ 번째 법안의 이념성향의 방향을 나타낸다.

식 (2.1)의 공간투표모형은 교육학 연구에서 사용되는 이모수 문항반응모형(two-parameter item response model)과 유사하다. 교육학 연구에서 $\boldsymbol{\beta}_{j}$ 는 문항 변별도 모수(item discrimination parameter)이며, $\alpha_{j}$ 는 문항 난이도 모수(item difficulty parameter)로 간주된다. 따라서 이 모형의 추정과 관 련한 많은 교육학 관련 연구들 (Bock과 Aitken, 1981)의 주요 관심사는 시험 또는 검사의 동등화(test equating)에 사용되는 $\boldsymbol{\beta}_{j}$ 측정에 관한 것이며, '능력' 모수 $\left(\mathbf{x}_{i}\right)$ 는 임의효과(random effects)로 취급된 다. 그러나 기명투표 결과를 분석하는 의정연구 맥락에서는 잠재된 특성 또는 능력 모수인 $\mathbf{x}_{i}$ 가 $i$ 번째 의원의 최대선호점이고 이것이 관심의 초점이 되는 모수이다.

오차가 의원과 기명투표에 대해 독립적이라는 가정 하에서 기명투표 분석에 활용되는 이모수 문항반응 모형의 우도함수(likelihood function)는 다음과 같이 정의될 수 있다.

$$
L(\mathbf{B}, \boldsymbol{\alpha}, \mathbf{X} \mid \mathbf{Y})=\prod_{i=1}^{n} \prod_{j=1}^{m} \Phi\left(\mathbf{x}_{i}^{\prime} \boldsymbol{\beta}_{j}-\alpha_{j}\right)^{y_{i j}} \times\left(1-\Phi\left(\mathbf{x}_{i}^{\prime} \boldsymbol{\beta}_{j}-\alpha_{j}\right)\right)^{1-y_{i j}},
$$

여기서 $\mathbf{B}$ 는 $j$ 번째 행 $\boldsymbol{\beta}_{j}^{\prime}$ 을 가진 $m \times d$ 행렬, $\boldsymbol{\alpha}=\left(\alpha_{1}, \ldots, \alpha_{m}\right)^{\prime}, \mathbf{X}$ 는 $i$ 번째 행 $\mathbf{x}_{i}^{\prime}$ 를 가진 $n \times d$ 행 렬, $\mathbf{Y}$ 는 $(i, j)$ 번째 요소 $y_{i j}$ 를 가진 관찰된 투표의 $n \times m$ 행렬이다. 이 모형은 가장 단순한 형태이며, 좀 더 정교한 모형을 만들기 위한 출발점이라고 할 수 있다. Clinton과 Meirowitz (2001)는 의제 종속 성(agenda dependence)을 연구하기 위해 이 분석틀을 약간 수정하여 사용한 바 있다.

추정을 위해서는 식별(identifiability) 문제의 해결이 필수적이다. 이 문제를 해결하기 위해 Rivers (2003)는 최대선호점 행렬 $\mathbf{X}$ 에 대해 사전제약(priori restriction)이 존재하는 다차원적 공간모형을 식 별하는 데 필요한 조건을 밝힌 바 있다. 일차원의 정책공간에서는 최대선호점 행렬 $\mathbf{X}$ 에 대해 독립적인 두 개의 선형제약조건이 필요한데 실제 기명투표 자료를 분석할 때 가장 일반적으로 활용될 수 있는 조 건들은 두 가지로 축약될 수 있다. 첫 번째 방법은 임의의 지점에서 의원 두 명의 위치를 제한하는 것이 다. 가령, 한 사람은 -1 , 또 다른 한 사람은 +1 에 위치시키는 것이다. 그리고 고정된 두 사람의 정확한 좌표는 데이터의 성격에 따라 달리할 수 있다. 참고로 $d$ 차원의 선택공간에서 최대선호점 $\mathbf{X}$ 에 대해 선 형적으로 독립적인 제약은 $d(d+1)$ 개 존재한다. 다시 말해, 2 차원에서는 의원 세 명의 위치를 고정시키 는 것이 필요하다. 따라서 높은 차원으로 올라갈수록 추정이 계속 어려워지나 일반적인 기명투표 분석 에서는 전통적으로 일차원을 가정하는 경우가 많기 때문에 보통 2 명의 의원 위치를 고정하는 것으로 식 별문제를 해결할 수 있게 된다.

식별을 위한 다른 한 가지 방법으로 표준화된 최대선호점을 사용하는 것이다(추정된 최대선호점들을 평 균 0(mean zero), 표준편차(standard deviation) 1로 맞추는 것이다). 이 식별방법은 원점을 기준으로 최대선호점이나 정책방향을 치환시킴으로써 진보와 보수적 의원들의 추정값의 부호가 일관되게 유지되 도록 해준다. 이 문제를 해결하기 위해서는 Clinton 등 (2004)는 미국 106대 상원의원 Ted Kennedy와 Jesse Helms 의원을 기준점으로 가정하고 두 의원의 위치를 -1 과 1 로 각각 고정하였다. 하지만 본 분 석에서는 한국 18 대 국회 전체 회기 동안 한나라당과 민주당을 대표할만한 의원이 명확하지 않다. 이 
러한 이유로 추정된 최대선호점들의 평균을 0 , 표준편차를 1 로 맞추는 표준화된 최대선호점을 사용하였 다.

\section{2. 모형추정과 확률적 추론}

고전적인 빈도론자(frequentist)의 접근방식과 달리, 베이즈 분석방법은 알려지지 않은 최대선호점과 다 른 모수들을 확률변수로 간주하고 이들에 대하여 사전확률분포(prior distribution)를 가정함으로써 사 전정보를 모형화 할 수 있다. 베이즈 정리(Bayes' Theorem)는 사후확률분포(posterior distribution)를 얻을 수 있도록 사전정보와 관찰된 자료(data)를 결합하는 방법을 제시해주며, 베이즈 분석방법은 의 원들 간의 상대적 위치에 대해 확률적 결론을 내릴 수 있게 해준다. 또한 베이즈 추정방식은 복잡한 모형의 추론에 있어 고전적 추정방식을 적용할 때 흔히 생길 수 있는 계산적 어려움을 해결할 수 있 게 해준다. 베이즈 방법은 추정에 있어 비표본정보(non-sample information)를 사용하는 단점이 있다 (Western과 Jackman, 1994). 그러나 기명투표 자료가 갖고 있는 정보의 양이 상당히 많기 때문에 주관 적으로 가정하게 되는 사전확률분포의 영향은 제한적이다 (Clinton 등, 2004).

기명투표 분석에 있어 베이즈 방법을 사용함으로써 얻을 수 있는 가장 큰 장점은 추정에 관한 계산적 어 려움을 마코프 연쇄 몬테 카를로(MCMC; Markov Chain Monte Carlo) 방법을 통해 해결할 수 있다는 점이다. 가령 $m$ 개의 기명투표에 대해 $n$ 명의 의원이 투표한 자료를 갖고 있다고 할 때, $d$ 차원의 공간모 형이론에서는 $p$ 가 $n d+m(d+1)$ 개의 모수를 갖는 통계모형을 생성한다 (Clinton 등, 2004). 예를 들 면, 100 명의 상원의원이 534 개의 법안에 투표한 105 대 미국상원의 표결행태를 분석한다고 할 때, 1 차 원만 고려한다고 하더라도 총 $1,168(100 \times 1+534 \times(1+1))$ 개 모수의 추정을 요하게 된다 (Clinton 등, 2004). 더욱이 차원이 높아지고 분석기간이 길어지면 모수의 수 또한 기하급수적으로 증가하게 된 다. 이런 점에서 베이즈 방법은 고전적 추정기법들로는 다루기 힘든 최대선호점과 실질적 가설들에 대 한 추론을 가능하게 해준다. 추가적으로, 본 논문에서 사용된 베이즈 모형과 추정과정은 보다 복잡한 모 형에 대하여도 쉽게 확장이 가능하다.

잘 알려진 바와 같이 일반적으로 고전적 추정방식을 적용할 경우 모수의 증가는 여러 가지 문제를 야 기한다. 이는 기명투표 분석에서도 예외가 아니다. 모수의 수가 표본크기의 함수일 때 최대우도 추정 량(maximum likelihood estimator)과 같은 기존 추정량은 최적의 특성들을 보여주지 못한다. 특히 정보행렬의 크기가 너무 커져 역행렬을 활용한 표준오차의 계산이 불가능해진다. Poole과 Rosenthal (1997) 또한 최대선호점 추정치의 표준오차를 계산하기 위해 불필요한 모수(nuisance parameter)인 법 안 모수를 추정된 값으로 고정시키는 방법을 사용했다. 그러나 저자 자신들도 밝힌 바와 같이 이렇게 계 산된 조건부 표준오차는 추정된 법안 모수들의 변동성을 고려하지 못하게 되어 실제 표보다 작은 추정값 을 주는 경향이 있다.

본 논문에서 활용하는 베이즈 추론 방법은 표본의 크기에 영향을 받지 않는다. 모수의 수는 실제 의원 수와 법안의 숫자에 의하여 결정되며, 베이즈 정리를 이용하여 계산된 모수의 사후확률분포에 바탕을 두 고 모수에 대한 추론을 하게 된다. 모수의 개별적인 추론을 위하여 사후확률분포의 여러 특성 값들을 계 산할 필요가 있는데 이를 위해 사후확률분포를 정상분포(stationary distribution)로 가지는 마코프 연 쇄(Markov Chain)으로 정의하고 이를 이용하여 사후확률분포로부터 표본을 추출해 관심이 되는 특성 값의 근사치를 계산한다.

본 논문의 베이즈 분석 과정은 다음과 같이 요약할 수 있다. 모든 모수에 대해 사전확률분포 가정을 필 요로 한다. 즉, 모든 $j$ 번째 법안에 대한 모수 $\boldsymbol{\beta}_{j}$ 와 $\alpha_{j}$, 그리고 모든 $i$ 번째 의원에 대한 최대선호점 $\mathbf{x}_{i}$ 에 대한 사전확률분포를 가정한다. 구체적으로는 프로빗 모형에서 사용된 오차항 $\epsilon_{i j}$ 에 대하여 표준정규오 
차(standard normal error)를 가정하고, 최대선호점(ideal point) $\mathbf{x}_{i}$ 과 모수 $\boldsymbol{\beta}_{j}, \alpha_{j}$ 에 대해서도 적절한 정규사전확률분포를 가정한다. 먼저 $\boldsymbol{\beta}_{j}$ 와 $\alpha_{j}$ 의 결합사전확률분포를 $N\left(\mathbf{t}_{0}, \mathbf{T}_{0}\right)$ 라고 가정하고, 본 연구 에서 $\mathbf{t}_{0}$ 는 모든 원소가 0 인 벡터이고 $\mathbf{T}_{0}$ 는 $\kappa \cdot \mathbf{I}_{d+1}$ 의 대각원소를 갖는 행렬을 가정하였다 $(\kappa$ 는 적당히 큰 양수). 다음으로 의원들의 최대선호점, $\mathbf{x}_{i}$ 는 정규사전확률분포 $N\left(\mathbf{v}_{i}, \mathbf{V}_{i}\right)$ (일반적으로 $\mathbf{v}_{i}$ 는 $\mathbf{0}$ 인 벡 터이고 $\mathbf{V}_{i}$ 는 $\mathbf{I}_{d}$ 의 대각원소를 갖는 행렬)로부터 독립적으로 추출되었다고 가정한다.

본 연구에서 사용하는 베이즈 모형은 인자모형(factor model)의 형태를 지니고 있고 많은 인자모형에서 와 마찬가지로 식별가능성(identifiability)의 문제를 지니고 있다. 즉 여러 다른 모수들이 동일한 모형 을 표현하고 있고 따라서 모형으로부터 모수를 식별할 수 없게 된다. 이 문제를 해결하기 위한 두 가지 방법이 있는데 (Clinton 등, 2004) 하나는 적절한 수의 특정 의원들에 대해서 아주 작은 $\nu$ 를 이용한 정 규사전확률분포 $N\left(\mathbf{a}_{i}, \nu \cdot \mathbf{I}_{d}\right)$ 을 사용함으로써 해당 의원들의 최대선호점을 $\mathbf{a}_{i}$ 로 고정시키는 것이다. 다 른 하나는 각 의원의 최대선호점들의 평균과 분산에 대하여 추가적인 조건을 가정하는 방법이다. 본 연 구에서는 18 대 국회의 전체 기간 동안 기준점이 되는 의원을 정하는 어려움이 있어 후자의 방법을 사용 하였다.

$\mathrm{MCMC}$ 방법을 활용하여 주어진 모형 하에서 계산된 모수들의 사후분포로부터 표본을 얻을 수 있다. 본 연구에서는 프로빗 모형의 용이한 추정을 위하여 $y_{i j}^{*}$ 라는 평균이 $\mathbf{x}_{i}{ }^{\prime} \boldsymbol{\beta}_{j}-\alpha_{j}$ 인 정규분포를 따르는 가상변수를 도입하여 $y_{i j}=\mathrm{I}\left(y_{i j}^{*}>0\right)$ 정의하고 $\mathrm{P}\left(y_{i j}=1\right)=p_{i j}=\Phi^{-1}\left(\mathbf{x}_{i}{ }^{\prime} \boldsymbol{\beta}_{j}-\alpha_{j}\right)$ 를 가정한다. 이 경우 $y_{i j}^{*}$ 의 사후확률분포는 $y_{i j}$ 의 관측값 $(0$ 또는 1$)$ 에 따라 $y_{i j}^{*}$ 의 정의역이 양수 또는 음수로 제약되는 절단 정규분포의 형태를 띄게 된다. 아래 $(1),(2),(3)$ 에 기술된 바와 같이, 정립된 선형회귀모형에 대 한 베이즈 분석방법을 활용한다. 추가적 잠재변수 $y_{i j}^{*}$ 은 현재의 모수 값들과 기명투표 자료가 주어졌을 때, 그것의 예측분포(predictive density)로부터 추출함으로써 얻게 된다. MCMC 알고리즘의 반복횟수 를 $t$ 라고 하면, 알고리즘의 $t$ 번째 반복은 아래에 제시된 일련의 사후조건부 확률들로부터의 표본추출절 차로 구성된다.

(1) $g\left(y_{i j}^{*} \mid y_{i j}, \mathbf{x}_{i}^{*}, \boldsymbol{\beta}_{j}, \alpha_{j}\right)$.

최초의 반복횟수 $t$ 에서 $\boldsymbol{\beta}_{j}^{(t-1)}, \alpha_{j}^{(t-1)}$ 그리고 $\mathbf{x}_{i}^{(t-1)}$ 를 알고 있다고 가정하고, 관측된 값 $y_{i j}$ 에 따 라 $y_{i j}^{*(t)}$ 는

$y_{i j}=0$ 인 경우

$$
y_{i j}^{*} \mid\left(y_{i j}=0, \mathbf{x}_{i}^{(t-1)}, \boldsymbol{\beta}_{j}^{(t-1)}, \alpha_{j}^{(t-1)}\right) \sim N^{-}\left(\mu_{i j}^{(t-1)}, 1\right) .
$$

$y_{i j}=1$ 인 경우

$$
y_{i j}^{*} \mid\left(y_{i j}=1, \mathbf{x}_{i}^{(t-1)}, \boldsymbol{\beta}_{j}^{(t-1)}, \alpha_{j}^{(t-1)}\right) \sim N^{+}\left(\mu_{i j}^{(t-1)}, 1\right) .
$$

결측처리된 기명투표 자료는

$$
y_{i j}^{*(t)} \sim N\left(\mu_{i j}^{(t-1)}, 1\right)
$$

로부터 추출한다. 여기서, $N^{+}$는 0 미만 부분이 절단된 정규분포, $N^{-}$는 0 이상 부분이 절단된 정규 분포를 나타낸다.

(2) $g\left(\boldsymbol{\beta}_{j}, \alpha_{j} \mid \mathbf{X}, y_{i j}^{*}\right)$.

$j$ 번째 법안에 대해 $(j=1, \ldots, m)$

$$
\left(\boldsymbol{\beta}_{j}^{(t)}, \alpha_{j}^{(t)} \mid \mathbf{X}, \mathbf{y}_{j}^{*(t)}\right)^{\prime} \sim N\left(\left(\mathbf{X}^{*^{\prime}} \mathbf{X}^{*}+\mathbf{T}_{0}^{-1}\right)^{-1}\left(\mathbf{X}^{*^{\prime}} \mathbf{y}_{j}^{*(t)}+\mathbf{T}_{0}^{-1} \mathbf{t}_{0}\right),\left(\mathbf{X}^{*^{\prime}} \mathbf{X}^{*}+\mathbf{T}_{0}^{-1}\right)^{-1}\right)
$$


여기서 $\mathbf{X}^{*}$ 는 $i$ 번째 행이 $\mathbf{x}_{i}^{*} \boldsymbol{\prime}=\left(\mathbf{x}_{i}^{(t-1)},,-1\right)$ 인 $n \times(d+1)$ 행렬이고, $\mathbf{y}_{j}^{*(t)}$ 는 $j$ 번째 기명투표에 대 한 잠재효용의 차이에서 추출된 $n \times 1$ 벡터이다. 또한 $\boldsymbol{\beta}_{j}$ 와 $\alpha_{j}$ 의 사전확률분포는 앞서 언급한 바 와 같이 $N\left(\mathbf{t}_{0}, \mathbf{T}_{0}\right)$ 이다. 이는 곧 $\mathbf{X}^{*}$ 에서 $\mathbf{y}_{j}^{*(t)}$ 의 '베이즈 회귀분석(Bayesian regression)'을 실행 하는 것이며 회귀계수 $\boldsymbol{\beta}_{j}$ 와 $\alpha_{j}$ 를 사후확률분포로부터 추출하는 것과 같다.

(3) $g\left(\mathbf{x}_{i} \mid y_{i j}^{*}, \boldsymbol{\beta}_{j}, \alpha_{j}\right)$.

잠재회귀식(latent linear regression)을 $w_{i j}=y_{i j}^{*}+\alpha_{j}=\mathbf{x}_{i}^{\prime} \boldsymbol{\beta}_{j}+\epsilon_{i j}$ 로 바꾸고 동시에 벡터로 표현 하면 $\mathbf{w}_{i}=\mathbf{B} \mathbf{x}_{i}+\boldsymbol{\epsilon}_{i}$ 로써 $n$ 개의 회귀식으로 표현된다. 이때 $\mathbf{B}$ 는 $j$ 번째 행이 $\boldsymbol{\beta}_{j}^{\prime}$ 로 주어진 $m \times d$ 행렬이다. 이를 통해 업데이트되어야 할 모수가 최대선호점 $\mathbf{x}_{i}$ 를 갖는 $n$ 개의 회귀식으로 아래와 같 이 표현된다:

$$
\mathbf{x}_{i}^{(t)} \mid \mathbf{B}, \mathbf{y}_{i}^{*} \sim N\left(\left(\mathbf{B}^{\prime} \mathbf{B}+\mathbf{V}_{i}^{-1}\right)^{-1}\left(\mathbf{B}^{\prime} \mathbf{w}_{j}+\mathbf{V}_{i}^{-1} \mathbf{v}_{i}\right),\left(\mathbf{B}^{\prime} \mathbf{B}+\mathbf{B}_{j}^{-1}\right)^{-1}\right) .
$$

모든 $\mathbf{x}_{i}(i=1, \ldots, n)$ 가 업데이트된 후, 추가적으로 $\mathbf{x}_{i}$ 를 평균이 $\mathbf{0}$ 이고 단위분산(unit variance)을 가지도록 재정규화(renormalization) 한다.

(1), (2), (3)의 분포로부터 프로빗 모형의 모수를 업데이트한다. 마지막 반복횟수 $t$ 에서 관심모수들의 현재값을 $\boldsymbol{\xi}^{(t)}=\left(\mathbf{B}^{(t)}, \boldsymbol{\alpha}^{(t)}, \mathbf{X}^{(t)}\right)$ 로 나타낸다면, 반복적인 $\mathrm{MCMC}$ 알고리즘은 $\boldsymbol{\xi}$ 의 극한분포(limiting distribution)로서 결합사후확률분포(joint posterior density)와 함께 마코프 체인을 구성하는 순열 $\boldsymbol{\xi}^{(1)}, \boldsymbol{\xi}^{(2)}, \ldots$ 을 생성한다. 결국, 알고리즘을 많이 반복했을 때 성공적인 표본 $\boldsymbol{\xi}$ 은 사후확률분포로부터 추출될 수 있다. 원칙적으로 $\mathrm{MCMC}$ 알고리즘은 모수의 숫자에 영향을 받지 않는다. 또한 이미 밝힌 바와 같이 어떤 사전확률분포를 사용하느냐는 최종결과에 큰 영향을 주지 않는다. Clinton 등 (2004) 역시 다수의 모수들에 대해 모호한 사전확률분포(vague prior)를 사용하여 실제로 사전확률분포가 사후 확률분포에 미치는 영향이 미미하다는 것을 보여주었다.

\section{3. 분석결과}

본 분석에서는 앞서 기술한 프로빗모형을 사용했으며, 의원들의 최대선호점이 평균 0 , 단위분산을 갖 는 제약을 부여했다. 본 분석에서는 총 2,389 개의 법안 $(m)$ 과 709,533 번의 개별 표결을 포함했다. 모든 의원들의 최대선호점 점수와 신뢰구간, 그리고 이 점수들을 기반으로 매긴 순위와 신뢰구간은 Figure 3.1 과 같다. 전체 의원들의 분포가 잘 드러나도록 전체 의원 중 9 명씩 나눈 결과를 표시했다. 모든 의원 들의 최대선호점 점수와 순위는 부록 Figure A.1과 Figure A.2에 첨부하였다.

우선 각 정당의 표결성향이 일반적으로 기대되는 순서로 정렬된 것을 볼 수 있다. 주요정당의 이념점수 와 순위의 중앙값으로 볼 때 민주노동당은 -2.727 또는 5 위(이정희 비례대표, 조승수 울산북구 의원), 민주당은 -1.133 또는 55 위 (김성순 서울송파병, 주승용 전남여수을 의원), 그리고 한나라당은 0.687 또 는 204위(박준선 경기용인기흥, 정몽준 서울동작을 의원)였다 (부록 Figure A.1과 Figure A.2 참조). 이 결과는 본 논문에서 적용한 방법론이 상당한 타당도가 있다는 것을 시사한다.

18 대 국회에서 가장 진보적인 표결성향을 보인 의원은 유원일(창조한국당, 비례대표), 곽정숙(민주노동 당, 비례대표), 홍희덕(민주노동당, 비례대표), 이정희(민주노동당, 비례대표), 조승수(민주노동당, 울산 북구), 강기갑(민주노동당, 경남사천), 권영길(민주노동당, 경남창원을) 의원 등으로 판명되었는데 유원 일 의원을 제외하고는 모두 민주노동당 소속이었다. 또 한 가지 주목할 점은 이념점수와 순위 모두에서 정범구 의원을 제외한 모든 민주당 소속 의원들의 $90 \%$ 신뢰구간이 민주노동당 소속의원들과 겹치지 않 는다는 것이다. 이는 민주당과 민주노동당 간에 이념적 성향 차이가 상당히 명확하다는 경험적 증거라 할 수 있다. 반면, 성윤환(한나라당, 경북상주), 정두언(한나라당, 서울서대문을), 공성진(한나라당, 서 
울강남을), 이인기(한나라당, 경북고령 성주 칠곡), 정옥임(한나라당, 비례대표) 등이 가장 보수적인 성 향의 의원들로 분류되었다.

\subsection{8대 국회 의원 소모임의 이념위치}

앞서 밝힌 바와 같이 일부 학자들이 그 동안 국회표결 결과분석에 회의적이었던 것은 강력한 당론투표로 인해 의원들 간에 유의미한 이념적 스펙트럼이 존재하지 않을 것이라는 선입견에 기인한다. 이 절에서 는 각 정당에서 특정한 성향을 가진다고 알려져 있는 의원 소모임들의 소속 의원들이 과연 소속 정당 주 류의원들의 이념과 유의한 차이를 보이는지 살펴본다. 이 분석결과는 한국 국회의 표결 행태에 있어 당 론투표 이외에 유의미한 이념적 스펙트럼이 존재하는지를 보여준다.

이를 위해 본 분석에서는 한나라당의 의원 소모임인 '민본 21 '과 '함께 내일로', 그리고 민주당 내의 의 원 소모임인 '국민과 함께하는 국회의원 모임(이하 국민모임)'을 분석대상으로 삼았다. '민본 21 '은 한나 라당 내 소장파 의원들의 모임으로 주로 초선의원들이 주도적으로 참여했으며 당 내에서 상대적으로 진 보적 성향을 표방했다. 반면 '함께 내일로'는 한나라당 내 대표적 친이계 의원들의 모임으로 한나라당 내에서도 상대적으로 매파성향이 강한 의원들이 참여했던 것으로 잘 알려져 있다. 따라서 '국민모임'은 민주당 내 강경 비주류 의원들의 모임으로 잘 알려져 있어 민주당 내에서도 상대적으로 진보성향이 강한 의원들이 다수 참여하고 있어 민주당 주류보다 상대적으로 더 진보적인 성향을 보일 것이라 예상할 수 있다. 각 모임에 소속된 의원들의 명단이 공식적으로 발표된 적은 없으나 언론보도에 나왔던 명단을 중 심으로 유력 언론사 국회출입기자의 검증절차 거쳐 확실히 각 소모임 소속으로 분류될 수 있는 의원들의 명단을 확정했다.

Figure 3.1에 나온 최대선호점의 두 측도('점수'와 '순위')를 종속변수로 회귀분석을 실행하였다. 우선 각 소모임에 속해 있는 두 정당의 이념성향을 통제하기 위해 한나라당과 민주당을 더미변수 $(0,1)$ 로 모 형에 포함했고, 세 소모임을 규정하는 더미변수들을 추가하였다. 따라서 이 모형에서 세 소모임의 더미 변수들은 각 소모임이 소속 정당의 다른 의원들보다 상대적으로 더 보수적인지 더 진보적인지를 보여준 다. 마지막으로 이 분석에서 사용된 이념성향의 측도들이 추정 값이라는 점을 고려하기 위해서 각 추정 값의 분산의 역수를 취해 가중치로 사용하였다 (Iyengar 등, 2009).

Table 3.1에서 볼 수 있듯이 각 의원 소모임들은 소속 정당의 다른 의원들과는 분명한 이념성향의 차이 를 보이고 있으며, 이것은 강력한 당론투표의 존재에도 불구하고 한국 의회에서도 충분히 의미 있는 정 도의 이념적 스펙트럼이 엄연히 존재한다는 것을 시사한다. 예상했던 것처럼 '민본 21 ' 소속 의원들은, 한나라당 평균보다 진보적인 성향을 보인 반면 $(b=-0.254, p$ 값 $<0.10)$, '함께 내일로' 소속 의원들은 한나라당 평균보다 보수적인 성향으로 투표한 것으로 나타났다 $(b=0.233, p$ 값 $<0.05)$. 반면 '국민모 임'은 민주당의 평균보다 상대적으로 더 진보적인 성향을 보였다 $(b=-0.420, p$ 값 $<0.01)$.

이러한 결과는 순위에 근거해서도 재검증 될 수 있었다. '민본 21 '의 경우, 한나라당의 다른 의원들과 비 교했을 때 약 60 등 가까운 차이를 보였다 $(b=-56.284, p$ 값 $<0.01)$. 분석에 포함된 전체 한나라당 소 속 의원의 숫자가 171 명임을 고려할 때, 이는 상당히 큰 차이라는 것을 알 수 있다. 마찬가지로 '함께 내일로' 소속 의원들의 경우 다른 한나라당 의원들과 비교해서 약 50 등 이상 보수적인 성향을 보였고 $(b=53.074, p$ 값 < 0.01) '민본 21 '과 '함께 내일로' 소속 의원들을 비교할 경우, 같은 한나라당이라도 평균 100 등 이상의 차이가 있다는 것을 의미한다. 실제로 '민본 21 '의 경우 한나라당 주류 이념보다 일 부 보수적인 성향의 민주당 의원들과 더 가까운 정도의 이념성향을 보인다고 할 수도 있다. 마찬가지로 '국민모임' 소속 의원들도 민주당의 다른 의원들과 비교했을 때 거의 30 등 가까이 더 진보적인 투표성향 을 보인다는 것을 알 수 있다. 분석에 포함된 18 대 국회 민주당 소속 의원의 수가 85 명이었다는 것을 고 
Table 3.1. Distances between factional groups in the 18th National Assembly: OLS estimates

\begin{tabular}{ccc}
\hline & 이념점수 & 이념순위 \\
\hline 상수 & $-.369^{* *}$ & $126.070^{* *}$ \\
& $(.088)$ & $(8.072)$ \\
한나라당 & $1.009^{* *}$ & $50.932^{* *}$ \\
& $(.099)$ & $(12.517)$ \\
민주당 & $-.773^{* *}$ & $-91.004^{* *}$ \\
& $(.115)$ & $(10.483)$ \\
민본21 & $-.254+$ & $-56.284^{* *}$ \\
함께 내일로 & $(.170)$ & $(20.407)$ \\
& $.233^{*}$ & $53.074^{* *}$ \\
국민모임 & $(.093)$ & $(19.209)$ \\
& $-.420^{* *}$ & -29.279 \\
표본수 & $(.213)$ & $(23.707)$ \\
수정 결정계수 & 297 & 294 \\
\hline
\end{tabular}

려하면 이것은 상당히 큰 차이라 할 수 있다.

\subsection{8대 국회 중추적(pivotal)의원들}

의원행태와 관련한 많은 연구들에서 중추의원(pivotal legislators)이란 개념이 매우 중요하게 다루어 져 왔다. 이것은 미국 상원에서 대통령의 거부권을 기각하기 위해서는 100 명 의원 중 $2 / 3$ 이상의 찬 성이 있어야 하고, 토론종결안(cloture motions)을 통과시키기 위해서는 의원 60 명의 표가 필요하기 때문이다. 이와 관련해 '정체구간(gridlock interval)' 개념도 중요한데 이는 의사진행방해축(filibuster pivot)과 거부권 축(veto pivot) 사이에 존재하는 지역으로 정의된다. 만약 진보적인 대통령일 경우에 정체구간은 비토 축(33번째 상원의원)의 왼쪽과 의사진행방해축( 60 번째 상원의원)의 오른쪽에 위치하 게 된다. 이론적으로는 현 정책을 바꾸려는 법안이 정체구간에 위치한다면 통과되기 어렵다는 것을 의 미한다. 이러한 이론적 예측을 위해 일반적으로 해당 의원들의 추정된 최대선호점을 사용해 정체구간을 계산한다 (Howell 등, 2000).

어떤 의원이 토론종결을 언급하는 위치에 있는지 또는 중앙에 위치한 의원인지 등을 결정하기 위해서 각 의원이 갖고 있는 최대선호점 순서통계량에 대한 사후확률분포를 살펴보았다. 우선, 의원들의 결합사후 확률 밀도로부터 의원들의 최대선호점 $\mathbf{x}_{i}$ 을 추출한 후, 표본추출된 최대이상점에 순위를 매기고, 어떤 의원이 중추인지 또는 관심의 순서통계량에 위치하는지를 기록했다. 마지막으로 최대선호점의 사후확 률분포로부터 반복적으로 추출된 표본들에 대해 $i$ 번째 의원의 최대선호점이 중추 또는 관심의 순서통계 량에 위치하는 횟수의 비율을 계산했다.

우선, 18 대 국회에서 중앙값 위치에 해당하는 의원들이 누구인지를 살펴보았다. Schickler (2000)에서 와 같이 중앙값 위치에 해당하는 의원들은 18 대 국회 전체의 이념성향을 평가하는 데 중요한 참고자료 로 활용될 수 있다. 이는 각 의원의 최대선호점의 순위가 149 번째가 되는 149 번째로 보수적인 의원의 사후확률을 계산하여 봄으로써 알 수 있다.

두 번째로 $3 / 5$ 거부권 축의 위치에 해당하는 의원들이 누구인지를 살펴보았다. 이 $3 / 5$ 거부권 축은 5 월 2 일 '국회선진화법'이 통과되면서 관심의 초점이 되고 있다. 국회선진화법은 속칭 '몸싸움 방지법'이라 하여 국회의장의 직권상정 권한을 제한하는 대신, '신속처리제'를 도입하는 것이 그 골자라 할 수 있다. 

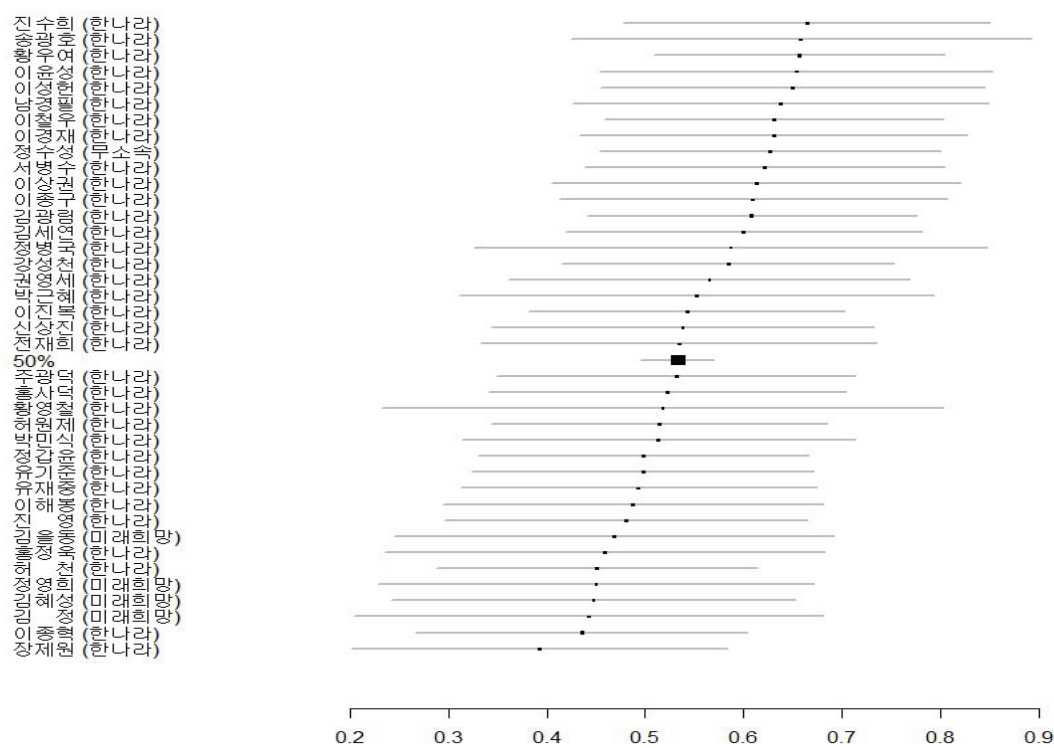

Figure 3.1. The pivotal legislator (149th) in the 18th National Assembly: Ideal point estimates

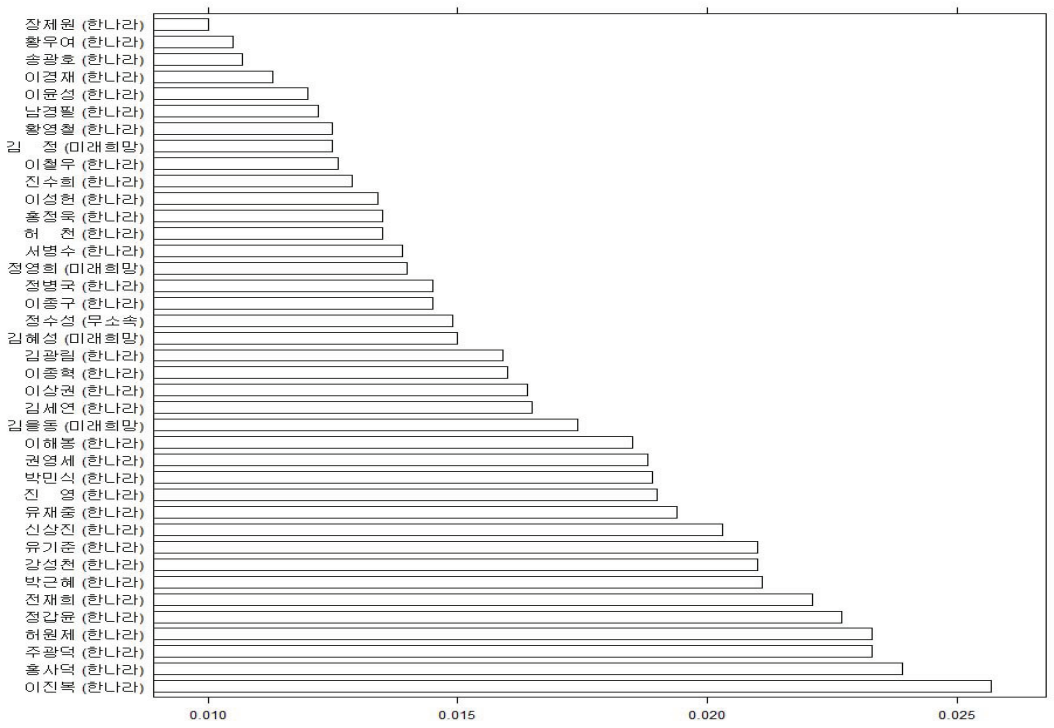

Figure 3.2. The pivotal legislator (149th) in the 18th National Assembly: Posterior probabilities

신속처리제를 도입할 경우 전체 재적의원 또는 상임위 재적위원 과반수가 요구하면, 상임위원장 또는 국 회의장이 안건을 무기명 투표에 부치고 재적의원 또는 상임위 재적위원 $3 / 5$ 이상이 찬성하면 안건으로 지정하게 된다. 따라서 국회선진화법에 따르면 $3 / 5$ 이 되는 179 번째로 보수적인 의원이 '몸싸움 방지축' 이 된다. 

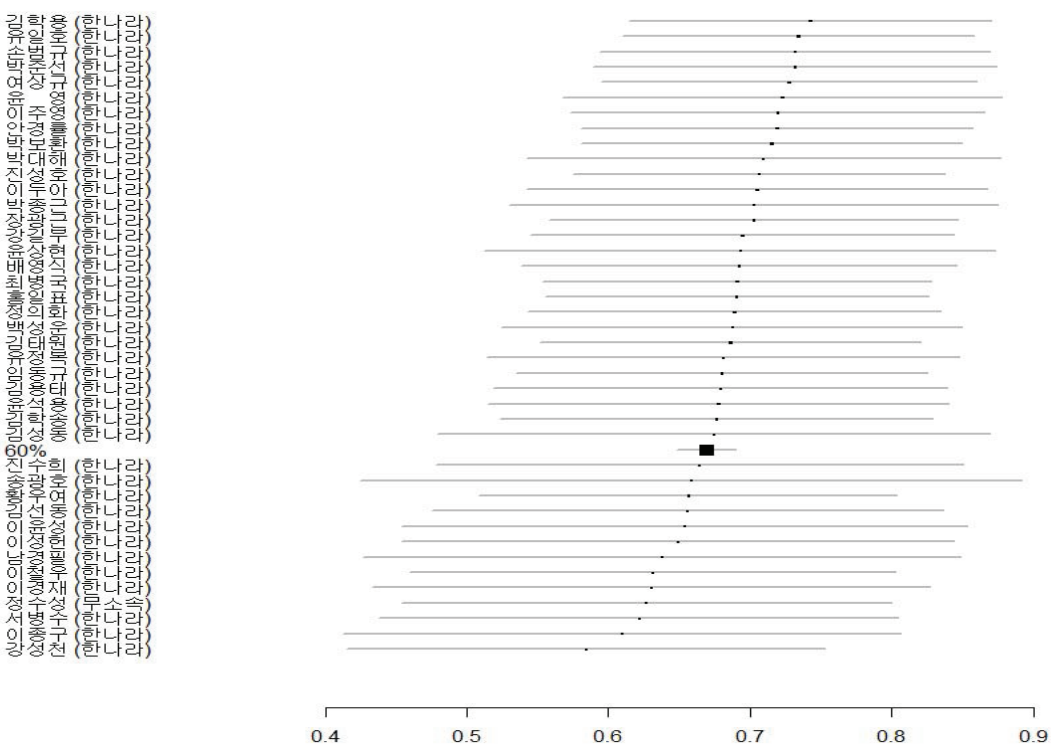

Figure 3.3. The veto pivotal (179th) Legislator of 18th National Assembly: Ideal point estimates

Figure 3.1와 Figure 3.2는 중앙값에 위치한 의원들의 정체성(최대선호점 점수)과 그 위치에 대한 사 후확률분포를 정리한 것이다. 우선 Figure 3.1 에서 볼 수 있듯이 18 대 국회에서 중앙값은 대체로 전재 희 의원(한나라당, 경기광명을)과 주광덕 의원(한나라당, 경기구리) 사이 정도에 위치한다는 것을 확인 할 수 있다. 개별 의원별로 보면 확실하게 중앙값 축(149 번째 의원)에 해당한다고 규정할 만한 의원은 없으나 이진복(한나라당, 부 산동래), 홍사덕(한나라당, 대구서구), 주광덕(한나라당, 경기구리), 허원 제(한나라당, 부산진구갑), 정갑윤(한나라당, 울산중구), 전재희(한나라당, 경기광명을), 박근혜(한나라 당, 대구달성), 강선천(한나라당, 비례대표), 유기준(한나라당, 부산서구), 신상진(한나라당, 경기성남중 원) 의원 등이 중앙값에 위치 할 가능성이 비교적 높은 의원들로 분류되었다.

Figure 3.3과 Figure 3.4는 '몸싸움 방지축'에 위치한 의원들의 정체성(최대선호점 점수)과 그 위치에 대한 사후확률분포를 정리한 것이다. Figure 3.3 에서 볼 수 있듯이 18 대 국회에서 $3 / 5$ '몸싸움 방지축' 은 김성동 의원(한나라당, 비례대표)과 진수희 의원(한나라당, 서울성동갑) 사이에 위치한다는 것을 알 수 있다. 개별 의원별로는 사후확률상으로 봤을 때 홍일표 의원(한나라당, 인천남구갑), 강길부 의원(한 나라당, 경북울주)이 이 축에 위치할 가능성이 가장 높은 의원들이며, 황우여(한나라당, 인천연수), 안 경률(한나라당, 부산해운대 기장을), 진성호(한나라당, 서울중량을), 배영식(한나라당, 대전중구), 장광 근(한나라당, 서울동대문갑), 최병국(한나라당, 울산남구갑), 김태원(한나라당, 경기고양덕양을), 이두 아(한나라당, 비례대표) 의원 등이 '몸싸움 방지축'에 해당할 가능성이 비교적 높은 의원들로 분류됐다.

\section{4. 결론}

본 연구에서는 최근 사회과학분야에서 관심이 높아지고 있는 베이즈 방법을 활용하여 기명투표 자료에 근거하여 국회의원들의 최대선호점을 추정하는 방법론을 제시하였다. 현대 의회연구에서 의회 구성원 들의 표결행태를 분석하여 최대선호점을 추정하는 것은 관련 연구의 발전을 위해 필수적인 작업이다. 


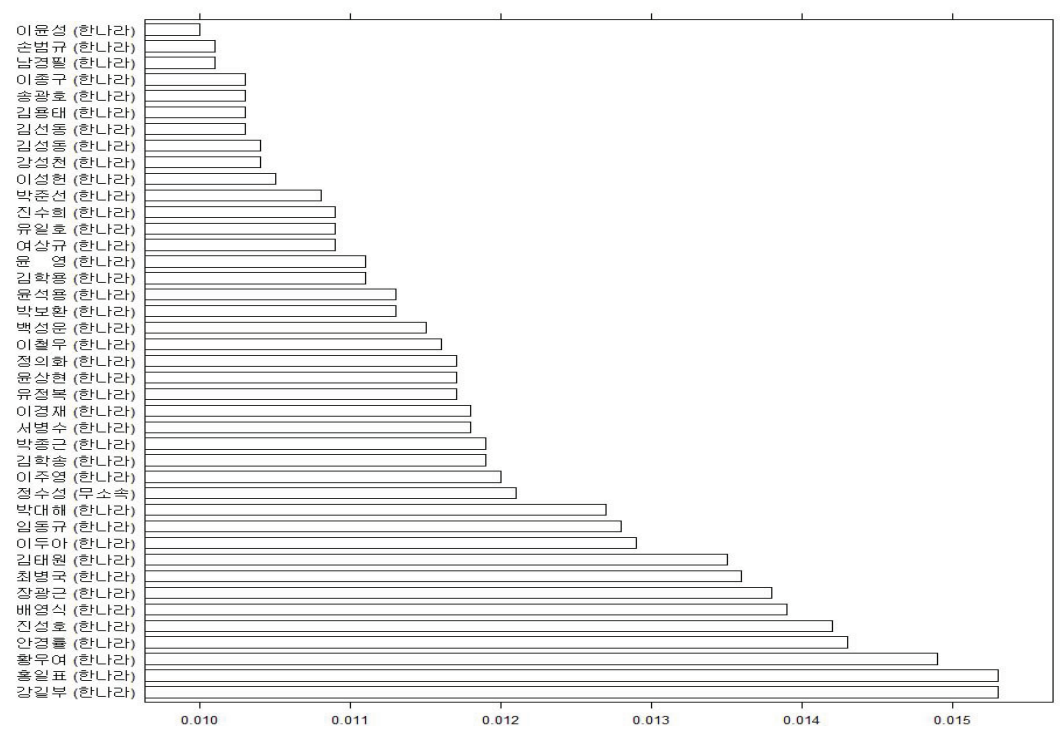

Figure 3.4. The veto pivotal (179th) legislator of 18th National Assembly: Posterior probabilities

많은 정치학 연구들이 기명투표 분석을 통해 추정된 최대선호점을 활용하여 의회가 유권자들의 이해를 대변하는 정도나 의원들의 입법행태와 관련된 이론들을 검증하고 있다. 따라서 전반적인 정치학 연구의 발전을 위해 최대선호점을 추정하는 방법론에 대한 고찰이 반드시 선행되어야 한다. 그러나 국내에서는 기명투표 자료를 활용한 연구들이 극히 제한적인 실정이며, 분석을 위한 방법론이 논의된 적도 거의 전 무한 상황이다.

Clinton 등 (2004)는 기명투표 분석을 위한 베이즈 방법론을 제시한 바 있다. 기존의 고전적인 빈도주 의적(frequentist) 접근방식과 달리, 베이즈 분석방법은 알려지지 않은 최대선호점과 다른 모수들을 확 률변수로 간주하고 이들에 대하여 사전확률분포를 가정하며 베이즈 공식은 사후확률분포를 얻을 수 있 도록 사전정보와 관찰된 자료를 결합하는 방법을 제시해 준다. 베이즈 방법론을 활용하면 복잡한 모형 의 추론에 있어 고전적 추정방식을 적용할 때 흔히 생길 수 있는 계산적 어려움을 마코프 연쇄 몬테 카 를로 방법을 통해 해결할 수 있고 자료의 양이 많을 경우 주관적으로 가정하게 되는 사전확률분포의 영 향도 최소화할 수 있다. 한편, 기명투표 분석에서는 모든 의원들이 최대선호점을 가지고 있고 각 법안 역시 '정책 위치'를 갖고 있기 때문에 많은 수의 모수를 추정해야만 한다. 그런데 고전적 빈도주의를 기 반으로 한 방법론들은 타당하지 않은 표준오차를 계산하게 되는 경우가 많고, 추정량의 일치성도 보장하 기 어려운 문제가 있다. 이런 점에서 베이즈 방법론은 고전적 추정기법들로는 다루기 힘든 최대선호점 의 추정과 이론적 가설들에 대한 실증적 추론을 가능하게 해준다.

본 논문에서는 Clinton 등 (2004)가 제시한 베이즈 방법론을 활용, 제 18 대 국회에서 처리된 2,389개의 법안에 대한 표결기록을 분석하여 18 대 국회의원 전원의 최대선호점과 신뢰구간을 추정했다. 우선 분 석결과를 살펴보면, 정당 간에 확연한 차이가 존재함을 확인할 수 있었다. 특히 가장 '보수적인' 민노당 소속 의원의 최대선호점 주변 신뢰구간이 민주당의 가장 '진보적인' 의원의 최대선호점과 서로 겹치지 않을 정도로 민노당과 민주당 간에 유의미한 차이가 보였고 이는 야당 간에도 엄연한 이념적 차이가 존 재함을 말해준다. 
분석결과의 타당성과 기명투표 분석의 유용성을 보여주기 위해 우선 잘 알려진 의원 소모임들의 표결행 태를 분석했다. 앞서 밝힌 바와 같이 그 동안 국내에서 기명투표 자료분석이 활발히 이루어지지 않은 것에는 당론투표가 존재하는 한국 의회정치의 특성상 기명투표 결과에 의미 있는 이념적 스펙트럼이 없 을 것이라는 막연한 회의론이 일조해 왔다. 본 논문의 분석결과는 18 대 국회에서 각 정당 내에 유의미 한 표결성향의 스펙트럼이 존재했다는 것을 실증적으로 보여주고 있다. '민본 21 '은 한나라당 주류보다 상대적으로 진보적인 성향으로 표결했던 것에 반해 친이계 의원 모임인 '다함께 내일로'는 상대적으로 보수적인 성향으로 표결한 것으로 나타났다. 마찬가지로 민주당 내에서 강경파 의원의 모임인 '국민모 임'은 민주당 주류와 비교했을 때 상대적으로 더 진보적인 성향으로 표결했던 것으로 드러났다. 이러한 결과는 일부 학자들의 인식과는 달리 각 정당 내에도 상당한 정도의 표결성향의 차이가 존재한다는 것을 보여주는 결과로 해석될 수 있다.

기명투표 자료분석의 가장 큰 학문적 의의는 의회정치를 둘러싼 다양한 가설의 검증을 가능케 해 준다는 점이다. 다시 말해, 연구자의 목적에 따라 본 연구의 분석결과를 기본 자료로 활용해 의회정치와 관련 된 다양한 이론적 가설들을 실증적으로 검증하는 것이 가능하다. 본 논문에서는 이러한 기명투표 분석 의 유용성을 보여 주는 하나의 예로 18 대 국회에서의 '중간축'과 '몸싸움 방지축'의 위치를 추정하고 이 축에 해당될 가능성이 높은 의원들을 어떻게 가려낼 수 있는지를 보여 주었다. 유사한 분석을 통해 도출 되는 결과는 향후 관련 의정연구에 활용될 수 있을 것으로 기대된다. 
부록
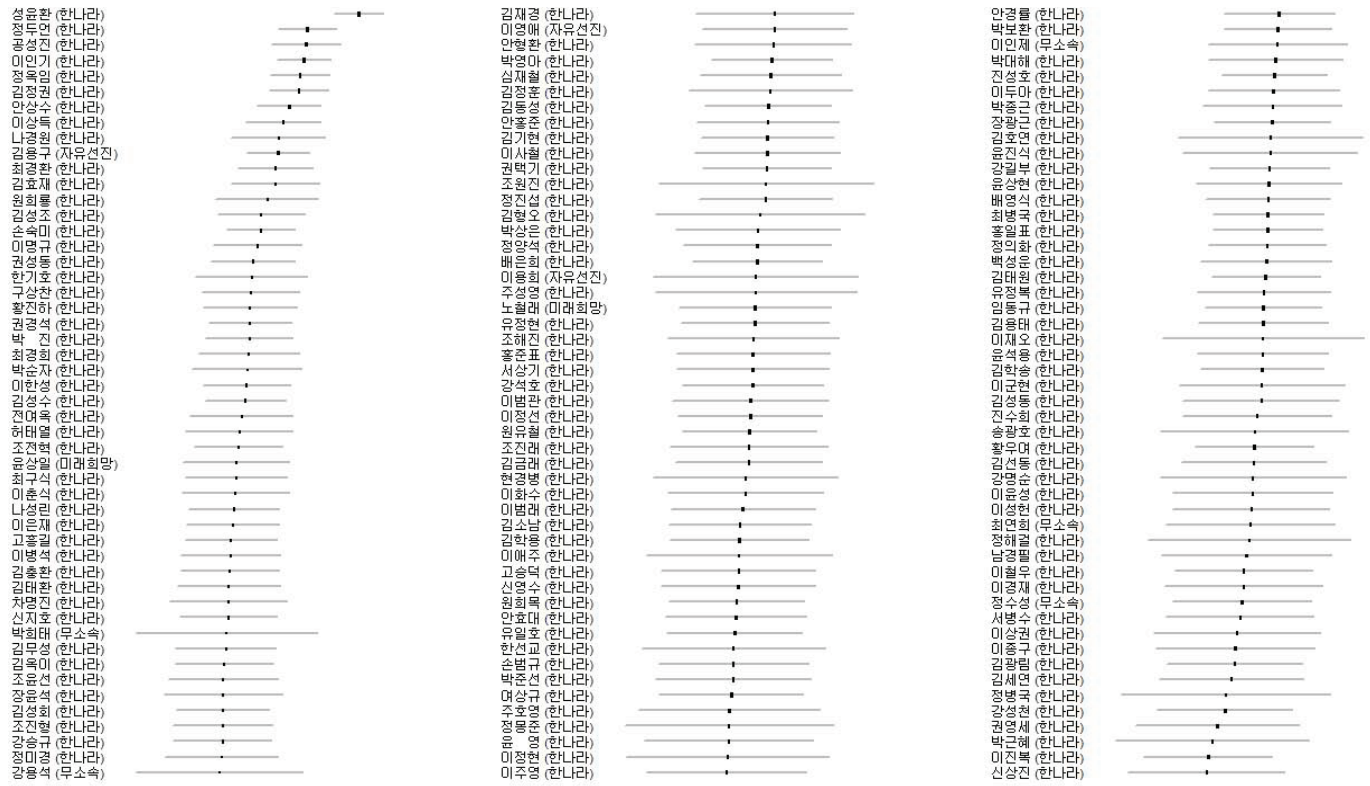

\begin{tabular}{lllllll}
\hline 0.6 & 0.7 & 0.8 & 0.9 & 1.0 & 1.1 & 1.2 \\
& & & & & &
\end{tabular}
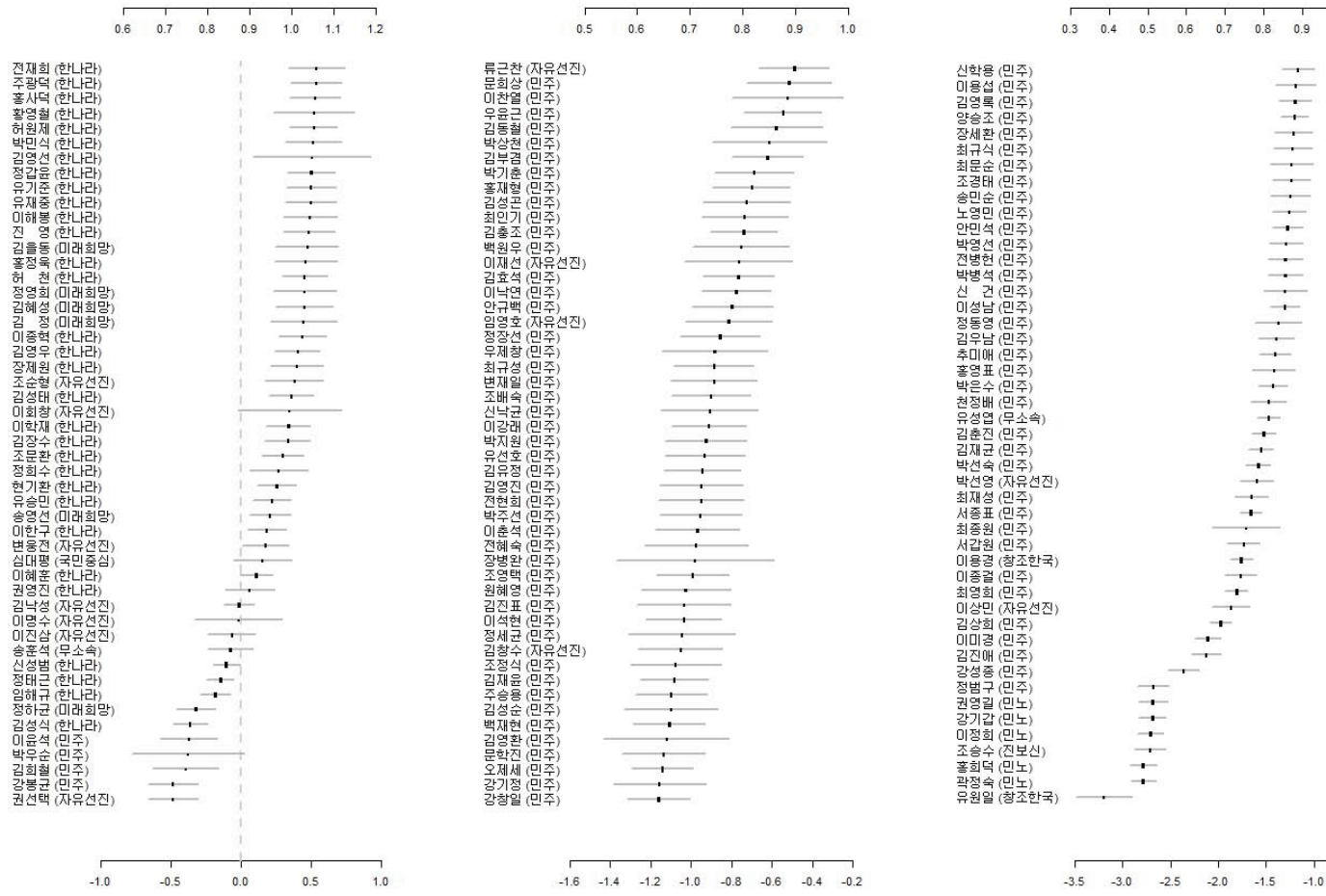

Figure A.1. Ideal point estimates of all legislators: The 18th National Assembly(90\% credible intervals) 


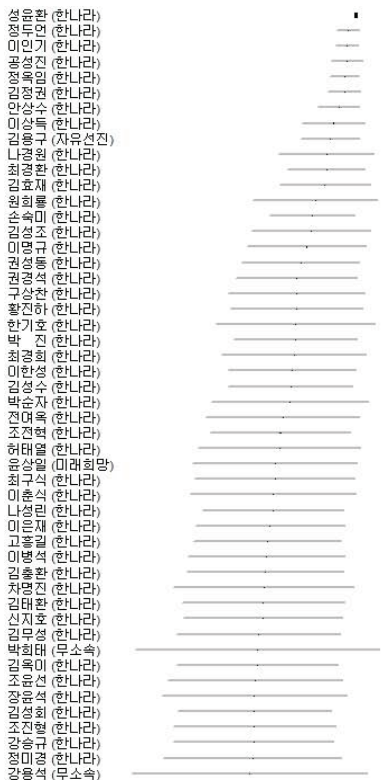

$\begin{array}{lllllllll}160 & 180 & 200 & 220 & 240 & 260 & 180 & 300\end{array}$

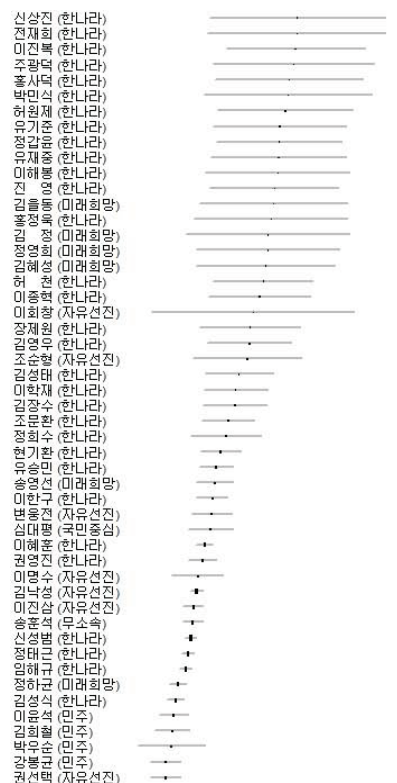

\begin{tabular}{rrrrrrr}
\hline 80 & 100 & 120 & 140 & 160 & 180 & 200
\end{tabular}
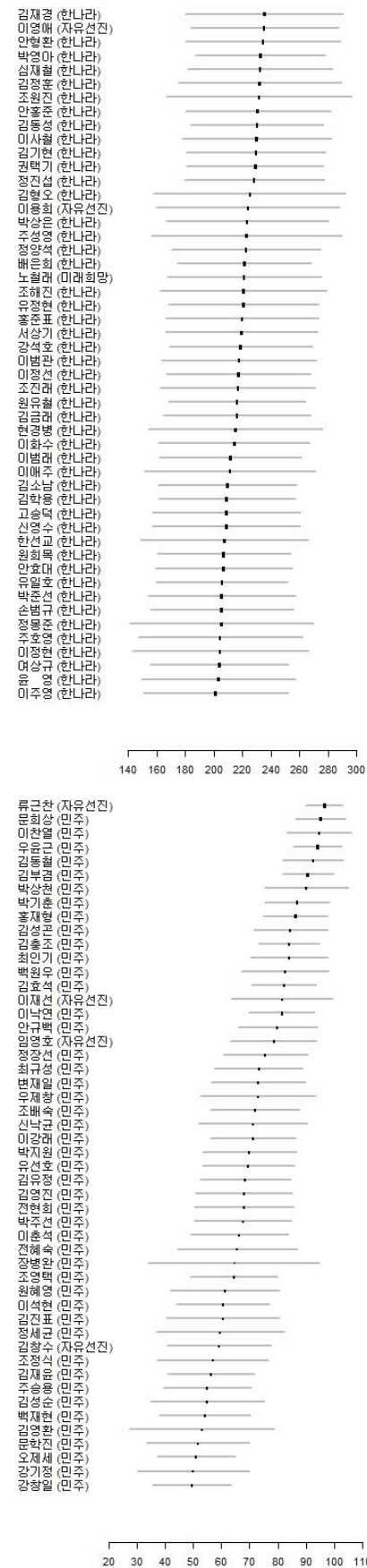

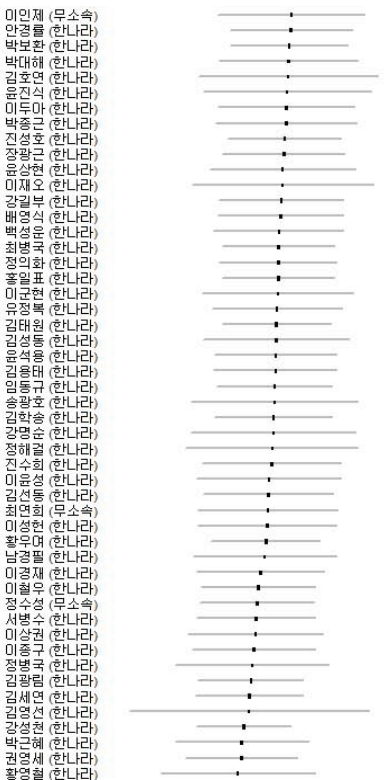

궣형엥첼ㄹㄹ (한난나라)
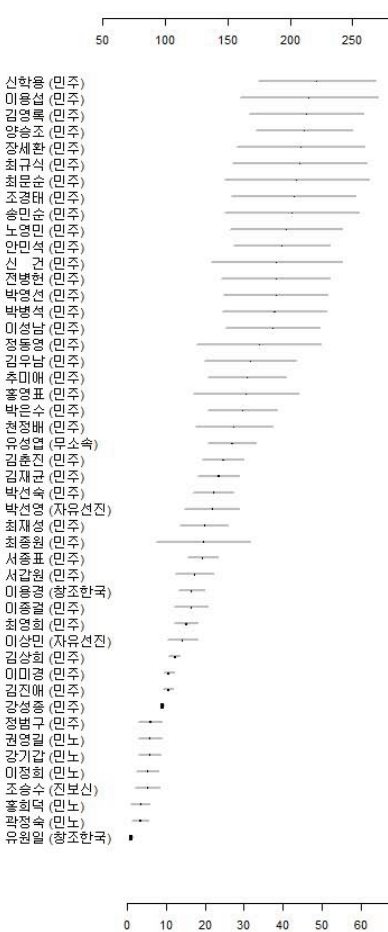

Figure A.2. Ideal point ranks of all legislators: The 18th National Assembly(90\% credible intervals) 


\section{References}

Abramowitz, A. I. and Saunders, K. L. (1998). Ideological realignment in the U.S. electorate, Journal of Politics, 60, 634-652.

Adams, G. D. (1997). Abortion: Evidence of issue evolution, American Journal of Political Science, 41, $718-737$.

Bock, R. D. and Aitken, M. (1981). Marginal maximum likelihood estimation of item parameters: Application of an EM algorithm, Psychometrika, 46, 443-459.

Carey, J. M. (2003). Discipline, accountability, and legislative voting in Latin America, Comparative Politics, 35, 191-211.

Carmines, E. G. and Stimson, J. A. (1989). Issue Evolution: Race and the Transformation of American Politics, Princeton University Press \& Princeton.

Clinton, J. D. and Meirowitz, A. (2001). Agenda constrained legislator ideal points and the spatial voting model, Political Analysis, 9, 242-259.

Clinton, J. D., Jackman, R. S. and Rivers, D. (2004). The statistical analysis of roll call data, American Political Science Review, 98, 355-370.

Davis, O. A., Hinrich, M. J. and Ordeshook, P. C. (1970). An expository development of a mathematical model of the electoral process, American Political Science Review, 64, 426-448.

Desposato, S. W. (2003). Parties for Rent Careerism, Ideology, and Party Switching in Brazil's Chamber of Deputies. Typescript, University of Arizona.

Downs, A. (1957). An Economic Theory of Democracy, Harper and Row, New York.

Heckman, J. J. and Snyder, J. M. (1997). Linear probability models of the demand for attributes with an empirical application to estimating the preferences of legislators, RAND Journal of Economics, 28, $142-189$.

Hix, S. (2001). Legislative behaviour and party competition in the European parliament: An application of nominate to the EU, Journal of Common Market Studies, 29, 663-688.

Howell, William, Scott, A., Charles, C. and Charles, R. (2000). Divided government and the legislative productivity of congress, 1945-94. Legislative Studies Quarterly, 25, 285-312.

lyengar, S., Jackman, S., and Hahn, K. S. (2009). Polarization in Thirty Seconds. Paper presented at the annual meeting of the Midwest Political Science Association, Chicago, Illinois.

Jackman, S. (2001). Multidimensional analysis of roll call data via Bayesian simulation: Identification, estimation, inference and model checking, Political Analysis, 9, 227-241.

Layman, G. C. (2001). The Great Divide: Religious and Cultural Conflict in American Party Politics, Columbia University Press, New York.

Londregan, J. (2000). Legislative Institutions and Ideology in Chile's Democratic Transition, Cambridge University Press. New York.

McCarty, N., Poole, K. T. and Rosenthal, H. (2001). The hunt for party discipline in congress, American Political Science Review, 95, 673-687.

Mercik, J. W. and Mazurkiewicz, M. (1997). Dimensional Analysis of Parliamentary Decisions, Technical University of Wroclaw, Technical Report.

Morgenstern, S. (2003). Patterns of Legislative Politics: Roll-Call Voting in Latin America and the United States, Cambridge University Press, New York.

Myagkovb, M. G. and Kiewiet, D. R. (1996). Czar rule in the Russian congress of peoples deputies, Legislative Studies Quarterly, 21, 5-40.

Noury, A. G. (2002). Ideology, nationality and euro-parliamentarians, European Union Politics, 3, 33-58.

Noury, A. G. and Mielcova, E. (1997). Roll-Call Voting in a Multi-Party Parliament: The Case of the Czech Parliament, Working Paper, Free University of Brussels, Belgium.

Poole, K. T. and Rosenthal, H. (1984). The polarization of American politics, Journal of Politics, 46, $1061-1079$.

Poole, K. T. and Rosenthal, H. (1997). Congress: A Political-Economic History of Roll Call Voting, Oxford University Press, New York.

Rivers, D. (2003). Identification of Multidimensional Item-Response Models, Stanford University, Type- 
script.

Rohde, D. W. (1991). Parties and Leaders in the Postreform House, University of Chicago Press, Chicago. Schickler, E. (2000). Institutional change in the house of representatives, 1867-1998: A test of partisan and ideological power balance models, American Political Science Review, 94, 269-288.

Schlesinger, J. A. (1985). The New American Party, American Political Science Review, 79, 1152-1169.

Voeten, E. (2000). Clashes in the assembly, International Organization, 54, 185-215.

Western, B. and Jackman, S. (1994). Bayesian inference for comparative research, American Political Science Review, 88, 412-423. 


\title{
제 18대 국회 기명투표 분석: 베이즈(Bayesian) 방법론 적용
}

\author{
한규섭 $^{a} \cdot$ 김윤응 $^{b} \cdot$ 임종호 $^{c} \cdot$ 임요한 $^{b} \cdot$ 권수현 $^{d} \cdot$ 이경은 $e^{e, 1}$ \\ ${ }^{a}$ 서울대학교 언론정보학과, ${ }^{b}$ 서울대학교 통계학과, ${ }^{c}$ Department of Statistics, lowa State University, \\ ${ }^{d}$ 고려대학교 정치외교학과, ${ }^{e}$ 경북대학교 통계학과
}

(2014년 2월 19일 접수, 2014년 4월 15일 수정, 2014년 6월 16일 채택)

\begin{abstract}
요 약
본 연구는 국회의 기명투표 분석에 적용될 수 있는 베이즈 방법론을 사용하여 지난 18 대 국회에서 처리된 2,389 개 의 법안에 대한 표결기록을 분석하였다. 기명투표 분석은 의정연구에 관련된 이론적 가설의 실증적 검증을 위한 기 초 데이터를 제공하는 경우가 많아 정치학 연구 전반의 발전을 위해 매우 중요한 의미를 가진다. 기명투표 분석에 있어 베이즈 방법론은 기존의 빈도주의적 방법론을 적용할 때 발생할 수 있는 통계적 문제들에 대한 훌륭한 대안을 제시한다. 본 연구에서는 Clinton 등 (2004)가 제안한 베이지언 방법론을 적용, 18 대 국회에서 처리된 모든 법안에 대한 표결기록을 분석하여 개별 의원들의 최대선호점(ideal points)과 신뢰구간을 추정했다. 본 연구에서 제안한 방 법론의 유용성 을 보여주기 위해 시범적으로 두 가지 경우에 대한 분석을 실시하였다. 하나는 널리 알려진 세 개의 의원 소모임의 최대선호점을 살펴봄으로써 한국 의회 내에 유의미한 표결성향의 스펙트럼이 존재하는지를 살펴보았 다. 다른 하나는 제안된 방법론을 활용하여 어떻게 이론적 가설의 검증이 이루어질 수 있는지를 보여주기 위해 18 대 국회의 ‘중간축'과 ‘몸싸움 방지축'의 위치와 두 중추적 위치에 해당할 가능성이 높은 의원들이 누구인지를 살펴보았 다.
\end{abstract}

주요용어: 기명투표, 베이즈 방법론, 18 대 국회, 최대선호점, 의원 행태와 선호.

이 논문은 한국연구재단 연구비(NRF-2012R1A $1 \mathrm{~A} 3013075)$ 의하여 연구되었음.

${ }^{1}$ 교신저자: (706-701) 대구 북구 대학로 80, 경북대학교 통계학과. E-mail: artlee@knu.ac.kr 